\title{
PROTOCOLANDO GÊNERO: PRÁTICAS, TECNOLOGIAS E FORMALIZAÇÕES DO GÊNERO NA VIVÊNCIA DO ESPAÇO TRANS (HC-UFPE)
}

\author{
PROTOCOLING GENDER: PRACTICES, TECHNOLOGIES AND \\ FORMALIZATIONS OF GENDER IN THE EXPERIENCE OF SPACE TRANS (HC- \\ UFPE)
}

\begin{abstract}
Débora Araújo de Vasconcellos ${ }^{1}$
${ }_{1}^{1}$ Universidade Federal de Pernambuco, Bolsista CNPq, Programa de Pós-Graduação em Sociologia, Brasil, e-mail: debora.vasconcellos15@gmail.com, ORCID: https://orcid.org/0000-0002-4799-0254
\end{abstract}

ARTICLE INFO

Article history:

Received 2020-05-31

Accepted 2020-11-30

Available online 2020-11-30
Palavras-chave: Gênero. Transgeneridade. Corpo. Performatividade.

Keywords: Gender; Transgender; Body; Performativity.

RESUMO. Este artigo é resultado do projeto de tese que tem como objetivo analisar as redes de normatização do gênero construídas a partir da relação entre transgêneros, profissionais $e$ tecnologias/protocolos envolvidos no processo transexualizador, na tentativa de contribuir para o aprofundamento no debate sobre gênero e corporalidade, além de pensar o debate sobre o social, pensando as associações feitas quando há diversos atores em rede. Metodologicamente circunscreve seu campo ao Espaço de Cuidado e Acolhimento Trans do Hospital das Clínicas (UFPE), optando pela realização de observação participante, entrevistas narrativas com usuárias/os e profissionais e análise documental dos protocolos/portarias envolvidos no processo transexualizador. Como base teórica para a concepção de gênero serão utilizados os trabalhos de Judith Butler e Anne Fausto-Sterling, medicalização do mundo moderno observado por Peter Conrad e Michel Foucault, e para pensar a estabilização e normalização de redes: Susan Leigh Star e Bruno Latour. A partir desses pontos serão suscitados questionamentos e possibilidades para pensarmos as tecnologias do gênero.

\begin{abstract}
This article is the result of a thesis project that aims to analyze the gender standardization networks built from the relationship between transgenders, professionals and technologies / protocols involved in the transsexualizing process, in an attempt to contribute to the deepening of the debate on gender and corporality, besides thinking about the debate about the social, thinking about the associations made when there are several actors in the network. Methodologically it circumscribes its field to the Trans Care and Reception Space at Hospital das Clínicas (UFPE), opting for participant observation, narrative interviews with users and professionals and documentary analysis of the protocols / ordinances involved in the transsexualizing process. As a theoretical basis for the conception of gender will be used the works of Judith Butler and Anne Fausto-Sterling, medicalization of the modern world observed by Peter Conrad and Michel Foucault, and to think about the stabilization and normalization of networks: Susan Leigh Star and Bruno Latour. From these points, questions and possibilities to think about the technologies of the genre will be raised.
\end{abstract}




\section{Introdução}

Segundo o dicionário, a palavra "Protocolo" é um substantivo masculino que teria na língua portuguesa alguns significados: o primeiro remonta ao selo utilizado pelos antigos romanos para a autenticação de registros públicos; a partir dele surgem os de uso corrente, que se referem à ata, registros de atos oficiais, como audiências, conferências, etc. No campo da saúde os protocolos se apresentam enquanto atas/registros de determinações oficiais para a realização autêntica de intervenções/tratamentos/procedimentos médicos, tanto para aspectos clínicos, ambulatoriais, cirúrgicos, terapêuticos, etc.

Esses protocolos são construídos a partir de estudos científicos relacionados a um determinado tratamento, somados à experiência prática na intervenção do caso em questão porparte dos profissionais e pelas respostas aos procedimentos daqueles que seriam os/as usuários/as do serviço de saúde. O protocolo garante que todos os profissionais atendam todos os pacientes seguindo os mesmos parâmetros, otimizando e padronizando a assistência. Porém, aonde quero chegar ao pensar "Protocolos de gênero"?

Foi durante minha pesquisa de campo no Espaço de Cuidado e Acolhimento Trans do Hospital das Clínicas (UFPE) quando diversas questões me foram suscitadas ao conviver com a rotina do espaço. Primeiramente, ao chegar lá buscava tentar compreender o processo transexualizador enquanto um protocolo aplicado na prática por parte daquele hospital que era ressignificado pela população trans através de suas vivências; porém percebi que naquele espaço apenas compreender como o processo transexualizador é aplicado e percebido pelas/os usuárias/os não era suficiente para as minhas inquietações.

Convivendo no espaço, observei que o mesmo possui uma rede múltipla de interações que definitivamente não o limitava enquanto espaço de atenção à saúde de uma população minoritária, nem tampouco o limitava enquanto uma relação de uma equipe multidisciplinar e o atendimento aos/às usuários/as do serviço como se define o processo transexualizador pelo SUS. As relações ali existentes perpassam uma rede múltipla de atores que durante a interação produzem sociabilidades e práticas importantes para compreendermos a complexidade que elementos como a saúde, o cuidado, a ciência, o corpo e o gênero perfazem ao se relacionarem e formarem, neste caso, aquele grupo.

E os protocolos de gênero? O processo transexualizador é um protocolo direcionado a procedimentos que envolvem diretamente aspectos de gênero, enquanto uma técnica de padronização e otimização de relações; sim, de relações, já que os mesmos garantem uma normatização sobre os procedimentos entre profissionais e usuárias/os, mas também a 
relação entre prática e ciência, entre artefatos/tecnologias - profissionais - usuários/as. Os protocolos são fundamentais para pensarmos as associações presentes na formação desse grupo, ainda mais quando se tem em vista a dimensão do gênero e do corpo. Tensiono um pouco mais, os próprios atores (profissionais, usuários/as, artefatos/tecnologias) formulam "protocolos" rotineiramente através de suas interações, no fazer social as concepções sobre o corpo e o gênero são constantemente transformadas.

Portanto, tenho como objetivo neste trabalho analisar as redes de normatização do gênero construídas a partir da relação entre transgêneros, profissionais e tecnologias/protocolos envolvidos no processo transexualizador. Compreendendo que o espaço hospitalar é um espaço de sociabilidades múltiplas e que nas relações entre profissionais-usuárias(os), profissionais-protocolos, usuários(as)-usuárias(os), profissionaistecnologias/artefatos, tecnologias/artefatos-usuários(as)-protocolos, há criações e classificações do corpo e do gênero, além de outras instâncias sociais, que complexificam as relações, funções e expectativas do espaço e dos sujeitos.

\section{Metodologia}

Como o objetivo deste trabalho consiste em analisar as redes de normatização do gênero construídas a partir da relação entre transgêneros, profissionais e tecnologias/protocolos envolvidos no processo transexualizador, utilizarei um conjunto de métodos para coleta de dados. Para isso será realizada uma observação participante no Espaço de Acolhimento e Cuidado Trans do Hospital das Clínicas da UFPE, entrevistas narrativas com usuárias/os e profissionais do espaço e coleta documental de protocolos utilizados pelos profissionais da instituição.

A observação participante é uma técnica de pesquisa que faz parte da história da pesquisa qualitativa, bastante empreendida pela antropologia como uma das práticas presentes na etnografia. Essa técnica consiste em uma inserção da pesquisadora no local de análise, observando os sujeitos em suas interações cotidianas na busca de compreender como se dão as práticas dentro da rotina do espaço, no caso como profissionais e usuárias/os interagem entre si, com o espaço e como as tecnologias/artefatos/protocolos se tornam presentes na interação. A escolha pelo Espaço de Cuidado e Acolhimento Trans do HC se dá por este ser o único centro de referência que realiza o processo transexualizador com cirurgias de redesignação sexual no Norte e Nordeste do Brasil. Pelos objetivos deste trabalho, o espaço apresenta uma interação entre profissionais da saúde e usuários/as do serviço possibilitando através da observação participante perceber como esses sujeitos 
constroem redes estabilizadas que afetam e perfazem as performatividades de gênero cotidianas.

Além disso, para maior aprofundamento serão realizadas entrevistas narrativas que visam apreender através das narrativas dos profissionais e usuárias/os como eles compreendem o gênero, a saúde, as tecnologias/artefatos disponíveis para as intervenções, como percebem o tratamento despendido a população trans e os limites e possibilidades dos protocolos médicos nas relações vividas no hospital. Esse material será posteriormente analisado através de uma análise de narrativa.

Há ainda um terceiro modo de coleta de dados, a pesquisa documental. Este método torna-se importante quando é visado por este projeto compreender os protocolos clínicos e terapêuticos utilizados pelos profissionais do Espaço de Cuidado e Acolhimento Trans, compreendendo que eles possuem aspectos do que se é compreendido socialmente como performatividade de gênero, saúde, cuidado, corpo, intervenção, parâmetro para atenção de sujeitos diversos. Assim, após a coleta do material documental, este será analisado através da análise de conteúdo proposta por Bardin.

\section{Desenvolvimento}

Como o objetivo deste trabalho é o de analisar as redes de normatização do gênero construídas a partir da relação entre transgêneros, profissionais e tecnologias/protocolos envolvidos no processo transexualizador, torna-se necessário demarcar determinados segmentos teóricos a partir dos quais pretendo iniciar a construção desta pesquisa.

Para a reflexão teórica desta pesquisa serão utilizadas para a compreensão de corpo e gênero as análises da filósofa feminista Judith Butler (2002) e da bióloga feminista Anne Fausto-Sterling (2000). Butler $(2002,2008)$ constrói sua percepção de gênero a partir da sua crítica a naturalização, tão facilmente atribuída, ao sexo e ao caráter construído (racional) do gênero. Para a autora, gênero não pode ser concebido enquanto uma essencialidade do sujeito, sua atuação é discursiva, o que não significa que não se materializa nos corpos. O discurso é feito e se inscreve na materialidade dos corpos.

Portanto, na perspectiva da autora gênero é percebido enquanto performatividade, em outras palavras, gênero se constitui através de gestos, atos, representações que se fazem por meio da rotineirização. É a ordinariedade que garante a sua inteligibilidade. Na sociedade moderna ocidental, a inteligibilidade, segundo a autora, se dá pelo sistema de matriz heterossexual, que garante as dicotomias macho-fêmea, homem-mulher, heterossexualhomossexual, evidenciando que esses pares são característicos de uma historicidade. Gê- 
nero, portanto, é temporal e circunscrito pelas associações de uma dada conjuntura histórica e social. Assim, compreendo que nas relações vivenciadas no Espaço de Cuidado e AcoIhimento Trans determinadas concepções de gênero estão sendo engendradas em uma rede de normatização que trazem relações múltiplas e uma performatividade de gênero relacionada a múltiplos atores, como por exemplo os profissionais, os usuários/as e os artefatos/tecnologias/protocolos.

Fausto-Sterling (2001/02) utiliza do pensamento da Butler (2002) para construir sua própria teoria, propondo a superação das dicotomias já postas e uma aproximação da biologia com as outras disciplinas. Segundo a autora, a separação das disciplinas durante o projeto de ciência moderna teve sua finalidade, porém é preciso superá-la através de uma teoria desenvolvimentista sistêmica. Esta terminologia é cunhada pela autora ao pensar em uma proposta analítica que relacione teorias de diversos autores de múltiplas áreas do saber que procuram pensar o desenvolvimento dos organismos (inclusive humano) enquanto um sistema mutuamente biológico e artificial, negando a existência de dois processos, muitas vezes vistos como antagônicos, um guiado pelos genes, hormônios e células do cérebro e outro pelo ambiente, experiência, ou forças sociais. (FAUSTO-STERLING, 2001/02).

Conrad (2007), no seu livro "The Medicalization of Society", apresenta como o processo de rápida expansão dos saberes biomédicos no século XX transformou diversos aspectos, antes vistos como desvios sociais, em patologias que necessitavam de tratamentos médicos. Nessa corrente se encontra a própria criação da terminologia transexualidade e sua inserção nos principais manuais de diagnósticos, além da própria criação dos manuais, como o $\mathrm{CID}^{1}$ e o $\mathrm{DSM}^{2}$.

Assim, no movimento de medicalização do mundo da vida, os indivíduos que se desviavam das normativas sociais de gênero impostas às suas genitálias e buscavam transitar para outra expressão foram enquadrados nessa classificação. Atualmente é bastante questionado esses aspectos patologizantes atribuído às identidades trans, por isso ao pensar as relações existentes no Espaço de Cuidado e Acolhimento Trans, principalmente ao problematizar as construções e associações dos sujeitos (profissionais e usuárias/os) com os protocolos/tecnologias/artefatos, torna-se essencial definir o conceito de medicalização e as percepções sobre os saberes biomédicos que circunscrevem o espaço e os atores das associações estudadas aqui.

Conrad (2007) define que medicalização é um conceito que descreve um processo onde problemas não médicos passam a ser definidos e tratados como e por problemas mé-

\footnotetext{
${ }^{1}$ Classificação Estatística Internacional de Doenças e Problemas Relacionados com a Saúde, se encontra atualmente na sua décima edição, mais conhecida por CID 10.

${ }_{2}^{2}$ Diagnostic and Statistical Manual of Mental Disorders, a transexualidade foi inserida no manual na sua terceira formulação, atualmente está na sua quinta, mais conhecido por DSM-5.
} 
dicos, normalmente apreendidos como doenças ou transtornos. Para o autor, na expansão dos problemas que são abarcados pelos saberes biomédicos alguns fenômenos são excepcionalmente visados, as condições que segundo eles são vistas como desviantes na nossa sociedade são as principais, como por exemplo transtornos mentais, distúrbios alimentares, diferenças de gênero e sexualidade, etc.

Dito isso, parto para o segundo autor de colaboração para a análise dos saberes biomédicos, Michel Foucault (1988). Já é de comum conhecimento que Foucault dedicou parte dos seus estudos para a compreensão do processo de nascimento e desenvolvimento dos saberes médicos, incluso como se constituem na sociedade moderna ocidental. Neste trabalho, busco articular a percepção do autor acerca do conceito de biopoder, para através dele pensar sobre a atuação dos protocolos, das tecnologias e artefatos proporcionados pelos saberes médicos nas relações com os profissionais e usuários/as do processo transexualizador.

O conceito "(...) serve para trazer à tona um campo composto por tentativas mais ou menos racionalizadas de intervir sobre as características vitais da existência humana." (RABINOW; ROSE, 2006, p.28), abrangendo o indivíduo e sua coletividade. As estratégias que atuam sobre a vida humana, os conhecimentos, práticas e intervenções são compreendidas pelo autor enquanto "biopolítica". Quais "verdades" estão sendo produzidas? Quais são as autoridades competentes para a produção dos protocolos e quais são os receptores? Como os indivíduos atuam e se legitimam dentro desse espaço?

Por fim, para pensar as relações estabelecidas por esses atores enquanto uma rede, ainda mais como produtores e produtos de redes de normatização do gênero, precisamos pensar o social de uma forma diferente: correlacionando percepções de gênero, ciência, práticas, protocolos, tecnologias/artefatos, enfim as associações aqui propostas. Para fundamentar tal asserção, trago dois sociólogos: Susan Leigh Star (1990) e Bruno Latour. Star (1999) ao discutir sobre o processo de classificação, afirma que:

(...) padrões e classificações, embora imbricados em nossas vidas, são normalmente invisíveis. Os formais e burocráticos arrastam atrás deles uma comitiva de permissões, formulários, numerais e o trabalho às vezes visível de pessoas que os ajustam para fazer com que as organizações funcionem sem problemas. Nesse sentido, eles podem se tornar mais visíveis, especialmente quando se desintegram ou se tornam objetos de contenção. Mas quais são essas categorias? Quem os cria e quem pode mudá-los? Quando e por que eles se tornam visíveis? Como eles se espalham? (STAR; BOWKER, 1999, p.2-3, tradução nossa) ${ }^{3}$

\footnotetext{
3 Texto original: (...) standards and classification, however imbricated in our lives, are ordinarily invisible. The formal, bureaucratic ones trail behind them the entourage of permits, forms, numerals, and the sometimes-visible work of people who adjust them to make organizations run smoothly. In that sense, they may become more visible, especially when they break
} 
Dessa maneira, quando me refiro aos protocolos os compreendo enquanto expressões burocráticas do sistema classificatório. Eles tornam visíveis a padronização. Entretanto, é com os questionamentos provocados pelos autores, que direciono o meu olhar para esses registros normativos. Nas relações entre transgêneros, profissionais e tecnologias/protocolos envolvidos no processo transexualizador, penso em como no Espaço de Cuidado e Acolhimento Trans as pessoas e os artefatos/tecnologias/protocolos produzem por meio de suas atividades relacionais tipos particulares de normatizações do gênero. Claro que essas normatizações estão inseridas em um contexto maior, em uma linguagem compartilhada socialmente que restringe e nomeia as compreensões dos atores sobre o que consistiria a "verdadeira" performatividade de gênero. Assim, pensando em um social associativo, enredado e relacional trago a perspectiva de Bruno Latour (2012) e sua teoria do Ator-Rede (ANT). Segundo o autor "(...) o adjetivo "social" não designa uma coisa entre outras como um carneiro negro entre carneiros brancos, e sim um tipo de conexão entre coisas que não são, em si mesmas, sociais." (LATOUR, 2012, p.23). Logo o social é circunstancial, associativo.

Através dessa lógica o autor percebe a importância de se pensar as associações para além dos atores humanos e apreender a forma como os não-humanos (objetos, artefatos, tecnologias, protocolos, animais, etc) interagem e atuam nas associações. Não há como negar que as interrelações entre os atores aqui citados (profissionais, usuárias/os, protocolos, artefatos, tecnologias) não estão apenas dadas, todos eles se afetam, suas ações se convergem e divergem. Para o autor o movimento desses atores é livre e acontece a partir de como a rede irá se dispor, às vezes essas movimentações serão estáveis, ora não. (LATOUR, 2012).

Entretanto, Latour (2012) tem recebido várias críticas de teóricas feministas (STAR, 1990) que compartilham com ele o campo dos estudos de ciência e tecnologia. Segundo essas autoras, a análise proposta na ANT acaba invisibilizando aspectos de gênero ao se colocar extremamente focalizada na inovação tecnológica (em seguir seus atores majoritariamente do gênero masculino) e por não questionar relações de poder que estariam intrínsecas aos fenômenos. Assim, não descartando a ideia de social proposta pela ANT, mas evidenciando a sua falha ao não compreender as marginalizações presentes no próprio processo de associação, trago a visão da socióloga: Susan Leigh Star (1990).

Star (1990) propõe uma análise fenomenológica das convenções sociais, refletindo sobre o processo de construção das técnicas, mas também sobre poder. Ela provoca Latour ao questionar sobre a irreversibilidade das redes e apresenta como os movimentos históri- 
cos são responsáveis pela estabilização de uma rede. As ações não são neutras, as ações dos actantes humanos é imbuída por moralidades e relações de poder. O olhar para o processo de classificação, de estabilização de redes, mas também de marginalização (consequência inerente ao processo de normatização) compreendido por Star, complementam a reflexão teórica que me proponho nesse trabalho.

\section{Resultados e Discussão}

Como a pesquisa aqui apresentada ainda está em andamento, ou seja, ainda está iniciando o processo de coleta empírica para posteriormente ocorrer a análise do material. Aqui nesse artigo, trago as discussões conceituais que até o momento estão sendo propiciadas pelo projeto. Portanto, ao pensar em protocolos, entendemos que eles garantem, na assistência à saúde, a possibilidade de realização de um procedimento padronizado, com garantias científicas, que podem ser aplicados para todos/as os/as usuários/as para o qual ele se aplica. Por exemplo, para a intervenção médica em pessoas com carcinoma de mama há a portaria nำ1.008/SAS/MS de 30 de setembro de 2015, que garante um procedimento eficaz e padronizado para as/os usuárias/os do SUS que procuram por esse atendimento hospitalar, assim uma diretriz de procedimentos é posta a fim de proporcionar melhores resultados e bem-estar para os pacientes.

A portaria (que é uma regulamentação oficial de âmbito nacional, que pode ser vista dessa forma enquanto um protocolo nacional, já que os protocolos possuem vários níveis, como: hospitalar, municipal, estadual, regional, nacional, internacional, etc.) deixa de forma explicita em seu texto que a criação de parâmetros de diagnóstico, tratamento e acompanhamento dos pacientes, são essenciais para o bem-estar dos/as pacientes. Com isso as Diretrizes Diagnósticas e Terapêuticas garantem procedimentos que são ditos enquanto seguros e fundamentais.

Para todos os atendimentos de tratamentos médicos, incluindo questões psicológicas, nutricionais, fisioterapêuticas etc.; torna-se necessário a formulação desses protocolos. Aqui proponho que eles proporcionam as associações tais quais são dadas nas relações entre profissionais-usuários(as)-tecnologias/artefatos/técnicas, o processo transexualizador por ser um protocolo poderia também ser visto por esse prisma.

Com o processo transexualizador, temos a interação de vários protocolos e diretrizes que se cruzam, como os protocolos para cirurgias como por exemplo a mastectomia e a histerectomia; protocolos locais de funcionamento do hospital credenciado habilitado para o processo; protocolos para hormonioterapia principal busca das/os usuárias/os. Entretanto 
durante o campo me surgiu a seguinte fala: "Quando vão montar um protocolo de hormonioterapia voltado para pessoas trans? O que sentimos não é igual ao de pessoas cis ${ }^{4}$ que fazem reposição hormonal. Quando farmacêuticos e endocrinologistas irão pensar em um tratamento pra gente? "5

Assim, os "protocolos de gênero" evidentemente presentes no caso do processo transexualizador, mas não somente presente nesse caso, reportam a corpos específicos, gêneros específicos que não são isentas de moralidade, cultura e sociabilidade dentre as quais os médicos estão inseridos na sua produção. Inclusive o próprio processo de classificação pode ser compreendido como parte da lógica humana. Segundo Susan Leigh Star e Geoffrey Bowker (1999), nem todas as classificações humanas recebem a formalidade de um protocolo, entretanto no fazer científico faz-se constantemente uma classificação formal de padronizações fenomênicas, estas classificações tendem a parecer neutras, porém estão enredadas em interpretações dos atores, estes correspondem a um período histórico e social específico. Podemos inferir que as noções (a linguagem) de gênero presente na sociedade estão agindo diretamente no processo classificatório dos/as cientistas. O curioso é que gênero e saber biomédico estiveram desde muito cedo associados.

O conceito de "Gênero" é atualmente bastante utilizado quando busca-se categorizar as expressões sociais impostas a corpos sexuados, desvinculando o aspecto "social", "cultural", daquele que seria o "natural", "biológico", conceituado, por sua vez, como sexo. Segundo Fausto-Sterling (2001/02), a dicotomia sexo-gênero se é feita e popularizada inicialmente através dos saberes biomédicos ${ }^{6}$, tendo como principais nomes os sexólogos John Money e Anke Ehrhard. Para estes havia uma necessidade de se fazer a dissociação desses aspectos já que ao estudarem pessoas intersexo, isso se tornava evidente. Para eles:

Sexo (...) se refere aos atributos físicos e é anatômica e fisiologicamente determinado. Viam o gênero como uma transformação psicológica do eu - a convicção interior de que se é homem ou mulher (identidade de gênero) e as expressões comportamentais dessa convicção. (FAUSTO-STERLING, 2001/02, p.15).

\footnotetext{
${ }^{4}$ A terminologia "cis" se refere ao termo "cisgênero", ele é utilizado para se referir aos indivíduos que se identificam com o gênero atribuído a ele desde o seu nascimento. Acredito ser importante a utilização dessa nomenclatura pela mesma surgir a partir de saberes construídos pela própria população trans, além do que a sua nomeação evidencia a ficção da "normalidade" posta pela medicalização das identidades trans e não dos antes ditos "normais", assim adotarei a terminologia "cisgênero" quando estiver falando daqueles que não são "transgêneros".

${ }^{5}$ Fala de um homem trans durante a minha observação de campo no Espaço de Cuidado e Acolhimento Trans no Hospital das Clínicas no ano de 2017.

6 O termo biomédico está sendo utilizado nesse texto enquanto um aglutinador dos saberes e conhecimentos apresentados pela medicina ocidental moderna e áreas correlatas como a biologia.
} 
Além dos estudos sobre intersexualidade, o termo também foi ganhando força dentro dos saberes biomédicos através dos estudos sobre a transexualidade encabeçados por Robert Stoller, Harry Benjamin, e o próprio John Money. Tanto com a intersexualidade e a transexualidade, os autores percebiam que havia indivíduos que possuíam corpos fisiologicamente não correlatos com as expressões sociais que seriam esperadas para estes. Assim, era necessário dissociar o social do natural para se dar identidade a esses indivíduos que se desviam da "normalidade", porém sem se questionar a naturalidade dos sexos/gêneros impostos; a dicotomia masculino-feminino não se quebra, uma vez que elas ainda são as únicas possibilidades de compreensão do corpo, do sexo e do gênero. (BENTO, 2006; FAUSTO-STERLING, 2001/02).

O conceito de gênero é incorporado pelas teóricas feministas da segunda geração e ganha verdadeiro destaque com o trabalho de Gayle Rubin e o seu sistema sexo/gênero. Importante perceber que o conceito chega inicialmente aos estudos sociais sem haver um questionamento acerca do sexo físico. Este, em uma visão dicotômica binária era tomado enquanto dado, o que precisava ser compreendido era o caráter social que, para essa geração, residia apenas no gênero. Por isso, segundo Fausto-Sterling (2001/02):

(...) as definições feministas de sexo e gênero deixavam aberta a possibilidade de que as diferenças masculino/feminino em funções cognitivas e comportamento podiam resultar de diferenças sexuais (...). Ao renunciar ao território do sexo físico, as feministas ficaram expostas a ataques renovados com base na diferença biológica. (FAUSTO-STERLING, 2001/02, p.17).

Com isso, à medida que os estudos feministas não questionavam a legitimidade biológica do sexo, os estudos biomédicos se intensificavam em perceber as diferenças sexuais como inerentes aos caracteres físicos e biológicos, estabelecendo as significações dadas as diferenças corporais enquanto verdades inquestionáveis.

Questionando essas premissas, a filósofa Judith Butler (2000) apresenta no seu livro "Bodies that matter" que a categoria sexo é desde o seu início uma categoria normativa, assim segundo a autora:

(...) "sexo" é um constructo ideal que é forçosamente materializado através do tempo. Ele não é um simples fato ou condição estática de um corpo, mas um processo pelo qual as normas regulatórias materializam o "sexo" e produzem essa materialização através de uma reiteração forçadas destas normas. (...) é que as normas regulatórias do "sexo" trabalham de uma forma performativa para constituir a materialidade dos corpos e, mais especificamente, para materializar o sexo do corpo, para materializar a diferença sexual a serviço da consolidação do imperativo heterossexual. regulatória. O "sexo" é, pois, não simplesmente aquilo que alguém tem ou uma descrição estática daquilo que alguém é: ele é uma das 
normas pelas quais o "alguém" simplesmente se torna viável, é aquilo que qualifica um corpo para a vida no interior do domínio da inteligibilidade cultural. (BUTLER, 2000, p.151-152)

Butler (2000) não nega as diferenças corporais, na verdade evidencia que a própria percepção a partir da qual essa diferença é percebida já está pautada em um determinado tempo histórico, por uma cultura determinada. No processo classificatório de diferenciação materializamos em nossos corpos tais aspectos e quando apontamos que a forma como pensamos as diferenças corporais através do sexo, estamos também produzindo um discurso sobre e materializado no corpo.

\section{Considerações Finais}

Compreendendo que o projeto se encontra na fase de organização teóricometodológica para a iniciação da pesquisa de campo no início de 2021, ainda não há resultados e conclusões de tal proposta. Entretanto, a partir do debate teórico suscitado por essa pesquisa, podemos apontar algumas considerações. Como as reflexões acerca das construções práticas e discursivas sobre o gênero está inevitavelmente presente em todo nosso cotidiano? Em um espaço como o hospitalar e de construção de cuidado e acolhimento da população trans, certos aspectos se tornam de extrema relevância. Como os protocolos estão produzindo discursos generificados? Quais verdades sobre gênero estão sendo produzidas na prática de usuárias/os e profissionais nesse espaço?

Quando nos propomos a analisar tal fenômeno sob a ótica de práticas estabilizadas em um processo de rede, onde vários atores estão se articulando sendo produto e produtor de tais discursos associados, abrimos um leque de possibilidades para entendermos como estamos produzindo cuidado, gênero, corpos e tecnologias, que acabam por modificar diariamente, mesmo que em pequenas proporções, o social. Ou seja, as implicações teóricas que trouxe ao longo do texto incitam para que possamos observar o Espaço Trans como um lócus de reprodução de uma inteligibilidade de gênero que perpassa desde os seus protocolos ao próprio atendimento e cotidiano do espaço, mas também é um espaço de potencialidade para novas práticas que possam vir a transformar as percepções do gênero existentes. 


\section{Agradecimentos}

Agradeço ao CNPq pelo financiamento dessa pesquisa através da modalidade de bolsa para pós-graduação (Doutorado). Agradeço também ao Espaço Trans do HC-UFPE e ao meu orientador Prof. Gustavo Gomes da Costa Santos.

\section{Referências}

BUTLER, Judith. Cuerpos que importan: Sobre los límites materiales y discursivos del «Sexo». Buenos Aires: Paidós. 2002.

Corpos que pesam: sobre os limites discursivos do sexo. In: LOURO, Guacira Lopes (Org.). O corpo educado: Pedagogias da sexualidade. 2 ed. Belo Horizonte: Autêntica, 2000.

Problemas de gênero: Feminismo e subversão da identidade. 2 ed. Rio de Janeiro: Civilização Brasileira, 2008.

CONRAD, Peter. The Medicalization of Society: On the Transformation of Human Conditions into Treatable Disorders. Baltimore: The Johns Hopkins University Press, 2007.

FAUSTO-STERLING, Anne. Sexing the Body: Gender Politics and The Construction of Sexuality. New York: Basic Books, 2000.

Dualismos em duelo. Cadernos Pagu. (17/18), pp. 9-79, 2001/02.

FOUCAULT, Michel. História da Sexualidade I: A vontade de saber. 13 ed. Rio de Janeiro: Edições Geral, 1988.

LATOUR, Bruno. Reagregando o social: Uma introdução à Teoria do Ator-Rede. Salvador: Edufba, 2012; Bauru, São Paulo: Edusc, 2012.

RABINOW, Paul; ROSE, Nikolas. O conceito de biopoder hoje. Política \& Trabalho Revista de Ciências Sociais, n.24, 27-57, 2006.

STAR, Susan Leigh. Power, technology and the phenomenology of conventions: on being allergic to onions. The Sociological Review, vol. 38, pp. 26-56, 1990.

STAR, Susan Leigh; BOWKER, Geoffrey C. Sorting Things Out: classification and its consequences. Cambridge; London: The MIT Press. 1999. 